\title{
Avaliação da ação antimicrobiana de soluções multiuso para desinfecção de lentes de contato hidrofílicas, in vitro
}

\author{
Antimicrobial efficacy assessment of multi-use solution to disinfect \\ hydrophilic contact lens, in vitro
}

\author{
Aline Cristina Fioravanti Lui ${ }^{1}$ \\ Adamo Lui Netto ${ }^{2}$ \\ Cely Barreto da Silva ${ }^{3}$ \\ Richard Hida ${ }^{4}$ \\ Thais Sousa Mendes 5 \\ Giovana Arlene Fioravanti Lui ${ }^{6}$ \\ Daniela Barbosa Gemperli ${ }^{7}$ \\ Enderson Dantas Vital ${ }^{8}$
}

\section{RESUMO}

Objetivo: Avaliar a influência da ação antimicrobiana das soluções multiuso para desinfecção de lentes de contato hidrofílicas. Métodos: Duas soluções multiuso denominadas solução A (poliquaternário-1 a $0,001 \%$ e miristamidopropil dimetilamina a $0,0005 \%$ ) e solução B (poliaminopropil biguanida a $0,0001 \%$ ) foram testadas em lentes de contato hidrofílicas contaminadas com Pseudomonas aeruginosa (ATCC27583), Staphylococcus epidermidis (ATCC1226), Klebsiella pneumoniae (ATCC13883), Staphylococcus aureus (ATCC25923) e Candida albicans (ATCC 10231) para verificar a quantidade de redução do crescimento dos microrganismos após o enxágue com as soluções. Foram seguidas as instruções preconizadas pelos fabricantes. Resultados: Houve redução de $90 \%$ do crescimento de Pseudomonas aeruginosa, Staphylococcus epidermidis, Staphylococcus aureus e Candida albicans. Não houve crescimento de Klebsiella pneumoniae. Conclusão: As soluções testadas neste trabalho mostraram redução do número de microrganismos testados.

Descritores: Lentes de contato hidrofílicas/efeitos adversos; Conjuntiva/microbiologia; Solucões; Pseudomonas aeruginosa/isolamento \& purificação; Staphylococcus epidermidis/isolatin \& purification; Stapylococcus aureus/isolamento \& purificação; Klebsiella pneumoniae/isolamento \& purificação; Candida albicans/isolamento \& purificação; Desinfecção; Ceratite/etiologia

\section{INTRODUÇÃO}

O uso de lentes de contato (LC) tem sido associado ao aumento do risco de infecção corneal ${ }^{(1)}$. A complicação mais temida é a ceratite infecciosa, que pode culminar em perfuração, cicatriz e perda permanente da visão ${ }^{(2)}$. Os principais agentes etiológicos das ceratites infecciosas em usuários de LC são Pseudomonas aeruginosa, Staphylococcus aureus e Staphyloccocus epidermidis ${ }^{(3-5)}$.

A incidência anual estimada de ceratite para cada 10.000 usuários é de 4,1\% para LC hidrofílicas de uso diário, 20,9\% para LC hidrofílicas de uso contínuo, $2 \%$ para LC rígidas de polimetilmetacrilato e $4 \%$ para LC rígidas gás permeáveis ${ }^{(6)}$.

Os mecanismos de defesa do olho baseiam-se na ação de limpeza proporcionadas pelas pálpebras durante o piscar, no epitélio corneal íntegro e no filme lacrimal, que contém imunoglobulinas e enzimas com atividade antimicrobiana $^{(7)}$. O uso de LC acarreta mudanças na superfície ocular, como alterações do filme lacrimal e do epitélio corneal, além de redução no 
aporte de oxigênio e troca de íons, que podem favorecer a infecção secundária ${ }^{(8)}$.

O contato de microrganismos com a superfície ocular, por meio da LC ou da solução contida no estojo contaminado, contribui para o desenvolvimento de infecção ${ }^{(9)}$. Estudos mostram que grande parte das contaminações das LC ocorre após o contato com as mãos dos usuários ${ }^{(10-11)}$. Assim, torna-se importante a higiene das mãos e o uso adequado das soluções para desinfecção das LC.

Soluções multiuso para LC têm sido cada vez mais utilizadas. Apresentam propriedades de limpeza, desinfecção, remoção de depósitos de proteínas e lubrificação, que simplificam as etapas dos cuidados por parte dos usuários ${ }^{(12-14)}$. Vários são os princípios ativos usados nas soluções multiuso, dos quais destacam-se o poliquaternário-1 a $0,001 \%$ (Polyquad ${ }^{\circledR}$ ), o miristamidopropil dimetilamina a $0,0005 \%$ (Aldox ${ }^{\circledR}$ ) e o poliaminopropil biguanida a $0,0001 \%\left(\text { Dymed }^{\circledR}\right)^{(14-15)}$.

O Dymed e o Polyquad são polímeros catiônicos com estrutura molecular grande, que atuam como conservante e desinfetante ${ }^{(12,16)}$. O Dymed é formado por unidades repetidas de biguanida separadas por uma cadeia de seis carbonos. Contém carga positiva no grupo biguanida e age de maneira semelhante à clorexidina, porém suas moléculas são maiores ${ }^{(12,16)}$. Sua ação inicia-se quando o composto atravessa a parede celular e outras membranas através de difusão passiva, atacando o citoplasma das bactérias ou a membrana plasmática dos fungos, desintegrando-as. $\mathrm{O}$ dano nas membranas é seguido pelo vazamento dos constituintes intracelulares, causando a morte dos microrganismos $^{(13)}$. O Polyquad é um composto solúvel em água e formado por mistura álcool/aquosa. O grande tamanho de suas moléculas previne a absorção através dos poros das LC hidrofílicas ${ }^{(12-13)}$. Atua no interior da membrana citoplasmática das bactérias e dos fungos, desencadeando adsorção e entrada do agente na parede celular. Depois, reage com os lipídeos e proteínas da membrana citoplasmática causando sua desorganização. Consequentemente, ocorre o extravasamento do material intracelular, degradação das proteínas e ácidos nucléicos e lise da parede bacteriana causada por enzimas autolíticas, culminando na perda estrutural e da integridade da membrana citoplasmática ${ }^{(16)}$. Sua ação é melhor contra bactérias, por isso atua em conjunto com o Aldox, que tem ação antifúngica ${ }^{(12-13)}$.

O "Food and Drug Administration" (FDA, Estados Unidos da América), em conjunto com o "International Standards Organization" (ISO 14729, Estados Unidos da América), têm padrões rigorosos para a aprovação da efetividade das soluções de desinfecção para LC ${ }^{(17-18)}$. Os testes desenvolvidos pelo ISO 14729 avaliam a interação direta da solução com o microrganismo, sem intermédio das LC. Depois de cumpridas e validadas as etapas pré-estabelecidas, é comprovada a efetividade do produto $^{(19)}$.

O objetivo deste estudo foi avaliar, in vitro, a ação antimicrobiana das soluções multiuso em LC hidrofílicas, contaminadas com Pseudomonas aeruginosa, Staphylococcus epidermidis, Klebsiella pneumoniae, Staphylococcus aureus e Candida albicans.

\section{MÉTODOS}

O estudo foi realizado no Laboratório de Microbiologia do Serviço de Controle de Infecção Hospitalar (SCIH) da Disciplina de Microbiologia do Departamento de Ciências Patológicas da Faculdade de Ciências Médicas da Santa Casa de Misericórdia de São Paulo (FCMSCSP) no período de junho a julho de 2007. Este estudo foi aprovado pelo comitê de ensino do SCIH e comissão científica do Departamento de Oftalmologia.

\section{Microrganismos estudados}

Foram selecionadas cepas com perfil microbiológico conhecido, padronizadas pela "American Type Culture Collection" (ATCC) de Pseudomonas aeruginosa (ATCC27583), Staphylococcus epidermidis (ATCC1226), Klebsiella pneumoniae (ATCC13883), Staphylococcus aureus (ATCC25923) e Candida albicans (ATCC10231).

\section{Meios de cultura}

- Placas com ágar Müeller-Hinton de 150 mm de diâmetro para todos os microrganismos.

- Placas de ágar sangue para cultura das soluções desinfetantes.

\section{LC e soluções multiuso}

Foram utilizadas 200 LC hidrofílicas (Hilofilcon B, com 59\% de composição hídrica, de uso programado) (Optilens, Bausch \& Lomb) e duas soluções multiuso disponíveis no mercado, denominadas Solução A, contendo Polyquad (poliquaternário-1 a $0,001 \%$ ) e Aldox (miristamidopropil dimetilamina a $0,0005 \%$ ) e Solução B contendo Dymed (poliaminopropil biguanida a $0,0001 \%$ ) (Tabela 1 ).

As soluções foram testadas de acordo com as instruções dos fabricantes. O período mínimo de permanência no estojo para desinfecção da solução A é de 4 horas e da solução B é de 6 horas.

\begin{tabular}{|c|c|c|}
\hline \multirow[t]{2}{*}{ Microrganismos } & Solução A & \multirow{2}{*}{$\frac{\text { Solução B }}{\text { Dymed }}$} \\
\hline & $\overline{\text { Polyquad + Aldox }}$ & \\
\hline Pseudomonas aeruginosa & 20 & 20 \\
\hline Staphylococcus epidermidis & 20 & 20 \\
\hline Klebsiella pneumoniae & 20 & 20 \\
\hline Staphylococcus aureus & 20 & 20 \\
\hline Candida albicans & 20 & 20 \\
\hline Total & 100 & 100 \\
\hline \multicolumn{3}{|c|}{$\begin{array}{l}\text { Fonte: Laboratório de Microbiologia do Serviço de Controle de Infecção } \\
\text { Hospitalar (SCIH) da Disciplina de Microbiologia do Departamento de Ciências } \\
\text { Patológicas da Faculdade de Ciências Médicas da Santa Casa de Misericórdia } \\
\text { de São Paulo (FCMSCSP), no período de junho a julho de } 2007 \text {. }\end{array}$} \\
\hline \multicolumn{3}{|c|}{$\begin{array}{l}\text { Polyquad }^{\circledR}=\text { poliquaternário - } 1 \text { a } 0,001 \% \text {; Aldox }{ }^{\circledR}=\text { miristamidopropil dimetilamina } \\
\left.\text { a } 0,0005 \% \text {; Dymed }{ }^{\circledR}=\text { (poliaminopropil biguanida a } 0,0001 \%\right)\end{array}$} \\
\hline
\end{tabular}




\section{Preparação do caldo para cultura}

As bactérias selecionadas foram descongeladas, semeadas em placas de ágar sangue e incubadas em caldo glicosilado por 24 horas, sob a temperatura de $35 \pm 2^{\circ} \mathrm{C}$. Após esse período, foram inoculadas em caldo nutriente "Brain Heart Infusion" (BHI), até a obtenção de 1,5 x $10^{8}$ unidades formadoras de colônias de bactérias por centímetro cúbico $\left(\mathrm{UFC} / \mathrm{cm}^{3}\right)$, o que corresponde ao padrão de turvação de 0,5 de Mc Farland ${ }^{(20)}$.

\section{Contaminação das $L C$}

Para cada bactéria, foram preparados $60 \mathrm{cc}$ do caldo, distribuídos em dois frascos estéreis com 20 LC em cada frasco. Após 2 horas, as LC foram retiradas do frasco com pinça estéril e semeadas na placa de Müeller-Hinton (S1). Todas as semeaduras realizadas neste estudo foram em forma de "in print", que consiste no contato das superfícies anterior e posterior da LC com a superfície da placa.

\section{Grupo controle}

A primeira semadura ( $\mathrm{S} 1)$ foi realizada após a contaminação das LC e usada como controle positivo, ou seja, com a presença de bactérias na placa.

\section{Semeadura dos microrganismos da LC contaminada}

Após S1, foi realizado o enxágue de 20 LC com a solução A, com luva estéril, durante 5 segundos. Dez LC de cada frasco foram enxaguadas com fricção e $10 \mathrm{LC}$ sem fricção. A seguir, foi realizada a segunda semeadura (S2). Todas as LC foram acondicionadas em estojos próprios, contendo a mesma solução com que foram enxaguadas, e os estojos foram mantidos fechados durante o período mínimo de permanência indicado pelo fabricante em temperatura ambiente $\left( \pm 25^{\circ} \mathrm{C}\right)$. O mesmo processo foi realizado para a solução B.

Após o período mínimo, as LC foram retiradas dos estojos com pinça estéril e semeadas novamente (S3). Em seguida, as LC foram enxaguadas por 5 segundos, com as respectivas soluções, mantendo-se o padrão anterior, e realizada a quarta semeadura (S4).

As soluções contidas nos estojos com as LC contaminadas foram semeadas em placas de ágar sangue para controle do crescimento bacteriano.

Todas as placas foram fechadas e incubadas em estufa por 24 horas à temperatura de $35 \pm 2^{\circ} \mathrm{C}$.

\section{Leitura dos resultados}

A leitura das placas contendo Pseudomonas aeruginosa, Staphylococcus epidermidis, Klebsiella pneumoniae e Staphylococcus aureus foi realizada após 24 horas. As placas negativas foram incubadas por mais 24 horas, totalizando 48 horas.

A leitura das placas contendo Candida albicans foi realizada após 96 horas.

Todos os resultados foram interpretados pelo método da técnica de comparação visual, que avalia o número de unida- des formadoras de colônias dos microrganismos. A interpretação foi realizada por três examinadoras, minimizando os erros $\alpha$ (variação individual) e $\beta$ (contaminação ou defeito do meio de cultura).

\section{RESULTADOS}

Houve redução de $90 \%$ de Staphylococcus aureus, Staphylococcus epidermidis, Candida albicans e Pseudomonas aeruginosa em S4 (Figura 1A). Não houve crescimento de Klebsiella pneumoniae em S3 e S4 (Figura 1B).
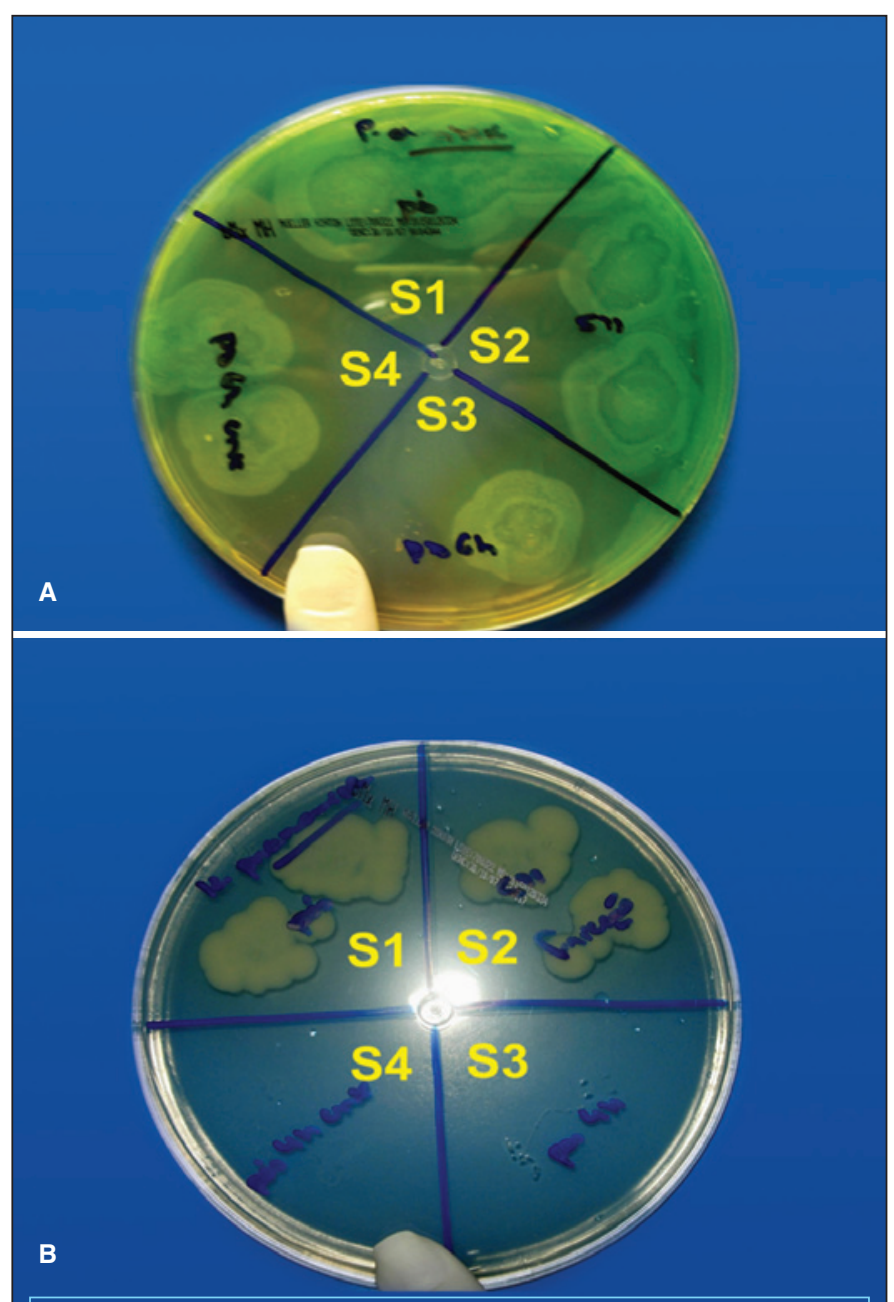

S1=semeadura após contaminação das LC (grupo controle); S2=semeadura após o primeiro enxágue da LC; $\$$ 3= semeadura após o período mínimo de permanência nos estojos; S4-semeadura após o segundo enxágue

Fonte: Laboratório de Microbiologia do Serviço de Controle de Infecção Hospitalar (SCIH) da Disciplina de Microbiologia do Departamento de Ciências Patológicas da Faculdade de Ciências Médicas da Santa Casa de Misericórdia de São Paulo (FCMSCSP), no período de junho a julho de 2007

Figura 1 - A) Placa de Müeller Hinton contendo Pseudomonas aeruginosa, mostrando redução de $90 \%$ em S4; B) Placa de Müeller Hinton mostrando que não houve crescimento de Klebsiella pneumoniae em S3 e S4 
A porcentagem de redução dos microrganismos após a lavagem com as soluções A e B pode ser observada no quadro 1.

Não foi observado crescimento de nenhum microrganismo nas placas ágar sangue contendo as soluções A e B dos estojos.

\section{DISCUSSÃO}

O presente estudo mostrou $90 \%$ de redução do crescimento de Pseudomonas aeruginosa, Staphylococcus aureus, Staphylococcus epidermidis e Candida albicans no S4 comparado com controle (S1). Klebsiella pneumoniae foi a única bactéria que não teve crescimento logo após o período mínimo de permanência estabelecida pelo fabricante (S3 e S4). Provavelmente, o fato da Klebsiella pneumoniae ser incapaz de aderirse ao plástico contribua para o resultado encontrado ${ }^{(21)}$.

A cultura das soluções em contato com a LC contaminada dentro do estojo após o período mínimo de permanência não apresentou crescimento microbiano, confirmando a efetividade da solução contra os microrganismos e mostrando que não houve contaminação.

Confronta-se o fato de ter-se obtido crescimento bacteriano e fúngico nas LC hidrofílicas (exceção Klebsiella pneumoniae), embora reduzido, e não nas soluções após o contato com as LC contaminadas. Uma explicação plausível seria a aderência das bactérias nas $\mathrm{LC}^{(22-23)}$. Este fato é reforçado pela observação de que a Klebsiella pneumoniae (a única bactéria que teve seu crescimento totalmente inibido no S3 e S4) não se adere ao plástico e, portanto, à LC (diferente dos outros microrganismos testados) $)^{(21)}$.

Este estudo realizou-se a partir de uma quantidade de microrganismos que é encontrada em contaminação de estojos e LC, sendo essa quantidade maior do que as ultilizadas nos outros estudos. O ISO 14729 parte de concentração 100 vezes menor do que a realizada neste estudo ${ }^{(18)}$. Porém, um outro estudo mostrou que $95 \%$ das LC em uso estão contaminadas ${ }^{(24)}$. Aponta-se o fato de que níveis de contaminação microbiana igual ou maior que $10^{8} \mathrm{UFC} / \mathrm{ml}$ são comuns em estojos de LC usados e que essa colonização influencia a contaminação das LC ${ }^{(25)}$. Por isso, optou-se por maior quantidade de microrganismos, pois mimetiza um ambiente mais fidedigno.

A formação do biofilme, que é definido como comunidade estruturada de microrganismos aderidos a uma superfície inerte (abiótica) ou viva (biótica), embebida em matriz de exopolissacarídeos, talvez seja a explicação para a colonização dessas bactérias nas LC, contribuindo para sua sobrevivência ${ }^{(26)}$. A colonização facilita a aderência e permanência dos microrganismos na superfície da LC, o que predispõe à infecção, principalmente em usuários de LC de uso prolongado ${ }^{(3,10,27)}$.

Com relação ao biofilme, estudos mostraram que a sua formação nos estojos para LC influencia a contaminação e nova formação de biofilme nas $\mathrm{LC}^{(9,28)}$. O biofilme é mais resistente aos agentes antimicrobianos, dificultando a completa remoção dos microrganismos, como foi observado neste trabalho.

Os microrganismos se aderem melhor em superfícies hidrofóbicas do que em superfícies hidrofílicas ${ }^{(3,5,22)}$. A presença de macromoléculas no filme lacrimal age sobre a superfície das LC, deixando-a mais hidrofílica. Dessa forma, o ambiente fica mais inóspito para os microrganismos, dificultando sua colonização. Nosso trabalho fez uso de LC hidrofílicas com $59 \%$ de conteúdo hídrico, o que talvez tenha contribuído para a grande redução dos microrganismos nas LC.

Com relação aos métodos de fricção ou não fricção da lente, não se observou diferença. Porém, o método de fricção pode causar microlesões nas LC, facilitando a aderência dos microrganismos e consequente formação de biofilme ${ }^{(22,29)}$. Em contrapartida, sabe-se que a remoção mecânica é mais eficaz para a limpeza de superfícies. Esse conflito demanda mais estudos para averiguar qual método deve ser adotado.

Este estudo mostra redução de $90 \%$ dos microrganismos presentes nas LC contaminadas com Pseudomonas aeruginosa, Staphylococcus epidermidis, Staphylococcus aureus e Candida albicans, após o uso correto das soluções. Resta enfatizar que usuários de LC devem ser alertados para o fato que, mesmo fazendo os procedimentos de rotina até agora estabelecidos, poderão estar sujeitos à presença dos microrganismos Pseudomonas aeruginosa, Staphylococcus epidermidis, Staphylococcus aureus e Candida albicans nas LC. Se a quantidade de microrganismos remanescentes nas LC for suficiente para causar infecção, a concepção dos métodos de desinfecção deveria ser revisada ${ }^{(30)}$.

\section{CONCLUSÃO}

A avaliação da ação antimicrobiana das soluções desinfetantes compostas de poliquaternário- 1 a $0,001 \%$ e mirista-

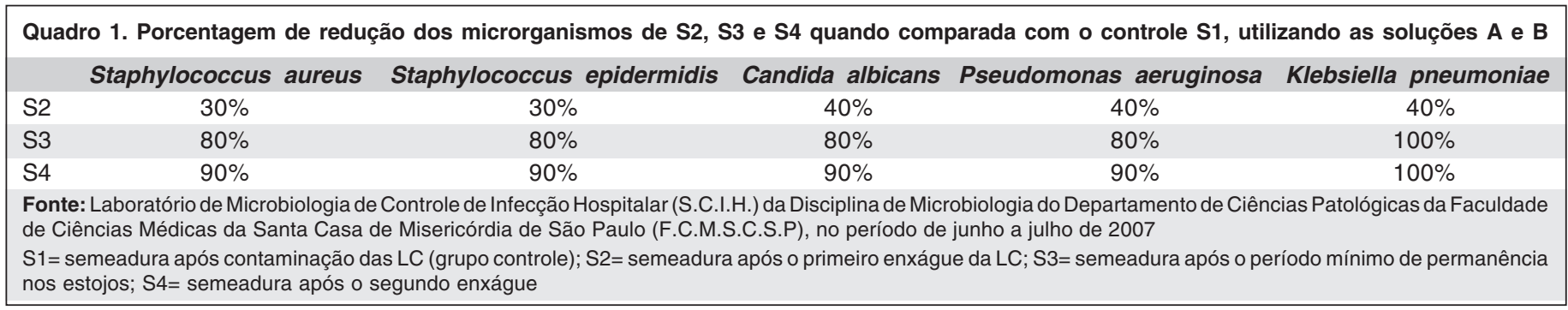


midopropil dimetilamina a $0,0005 \%$ e de poliaminopropil biguanida a $0,001 \%$ mostrou redução de $90 \%$ do número de Pseudomonas aeruginosa, Staphylococcus epidermidis, Staphylococcus aureus e Candida albicans nas LC hidrofílicas contaminadas.

No caso da Klebsiella pneumoniae, a redução foi de $100 \%$.

\section{ABSTR ACT}

Purpose: To evaluate the efficacy of disinfecting solutions in hydrophilic contact lenses (CL). Methods: Two multi-use solutions denominated solution A $(0.001 \%$ polyquaternium- 1 and $0.0005 \%$ myristamidopropyl dimethylamine) and solution B $(0.0001 \%$ polyaminopropyl biguanide $)$ were used. The solutions were tested in hydrophilic contact lenses infected with Pseudomonas aeruginosa (ATCC27583), Staphylococcus epidermidis (ATCC1226), Klebsiella pneumoniae (ATCC13883), Staphylococcus aureus (ATCC25923) and Candida albicans (ATCC 10231) and the decrease in microorganisms growth after the hydrophilic contact lenses were cleaned with the respective solutions was verified. The manufacture's instructions were followed. Results: A decrease of 90\% of Pseudomonas aeruginosa, Staphylococcus epidermidis, Staphylococcus aureus, Candida albicans and a decrease $100 \%$ of Klebsiella pneumoniae was observed. Conclusion: The solutions decreased the amount of microorganisms tested.

Keywords: Contact lenses, hydrophilic/adverse effects; Conjuctiva/microbiology; Solutions; Pseudomonas aeruginosal isolation \& purification; Staphylococcus epidermidis/isolation \& purification; Stapylococcus aureus/isolation \& purification; Klebsiella pneumoniae/isolation \& purification; Candida albicans/isolation \& purification; Disinfection; Keratitis/etiology

\section{REFERÊNCIAS}

1. Fleiszig SM, Efron N. Microbial flora in eyes of current and former contact lens wearers. J Clin Microbiol. 1992;30(5):1156-61.

2. Callegan MC, Engelbert M, Parke DW 2 $2^{\text {nd }}$, Jett BD, Gilmore MS. Bacterial endophthalmitis: epidemiology, therapeutics, and bacterium-host interactions. Clin Microbiol Rev. 2002;15(1):111-24.

3. Cowell BA, Willcox MD, Schneider RP. A relatively small change in sodium chloride concentration has a strong effect on adhesion of ocular bacteria to contact lenses. J Appl Microbiol. 1998;84(6):950-8.

4. Krachmer JH, Mannis MJ, Holland EJ. Cornea. London: Elsevier Mosby, 2005. Cap 107, Complication of Contact Lens Wear; 1329-3

5. Vermeltfoort PB, Rustema-Abbing M, De Vries J, Bruinsma GM, Busscher HJ, Van Der Linden Ml, et al. Influence of day and night wear on surface properties of silicone hydrogel contact lenses and bacterial adhesion. Cornea. 2006;25(5):516-23.

6. Poggio EC, Glynn RJ, Schein OD, Seddon JM, Shannon MJ, Scardino VA, et al. The incidence of ulcerative keratitis among users of daily-wear and extended- wear soft contact lenses. N Engl J Med. 1989;321(12):779-83. Comment in: N Engl J Med. 1989;321(12):824-6; N Engl J Med. 1990;322(10):700-1.

7. Klotz SA, Penn CC, Negvesky GJ, Butrus SI. Fungal and parasitic infections of the eye. Clin Microbiol Rev. 2000;13(4):662-85.

8. Dannelly HK, Waworuntu RV. Effectiveness of contact lens disinfectants after lens storage. Eye Contact Lens. 2004;30(3):163-5. Comment in: Eye Contact Lens. 2005;31(4):179; author reply 179 .

9. Mclaughlin-Borlace L, Stapleton F, Matheson M, Dart JK. Bacterial biofilm on contact lenses and lens storage cases in wearers with microbial keratitis. J Appl Microbiol. 1998;84(5):827-38.

10. Choo J, Vuu K, Bergenske P, Burnham K, Smythe J, Caroline P. Bacterial populations on silicone hydrogel and hydrogel contact lenses after swimming in a chlorinated pool. Optom Vis Sci. 2005;82(2):134-7.

11. Gopinathan U, Stapleton F, Sharma S, Willcox MD, Sweeney DF, Rao GN, et al. Microbial contamination of hydrogel contact lenses. J Appl Microbiol. 1997; 82(5):653-8.

12. Ghanen CC, Kara-José N. Lentes de contato na clínica oftalmológica. $3^{\underline{a}}$ ed. Rio de Janeiro: Cultura Médica; 2005.

13. Moreira SMB, Moreira H, Moreira L. Lente de contato. $3^{\underline{a}}$ ed. Rio de Janeiro: Cultura Médica; 2004; Cap 27; Limpeza e Assepia das Lentes Hidrofílicas, 187 97. 14. Codling CE, Maillard JY, Russell AD. Aspects of the antimicrobial mechanisms of action of a polyquaternium and an amidoamine. J Antimicrob Chemother. 2003;51(5):1153-8.

15. Rosenthal RA, Dassanayake NL, Schlitzer RL, Schlech BA, Meadows Dl, Stone RP. Biocide uptake in contact lenses and loss of fungicidal activity during storage of contact lenses. Eye Contact Lens. 2006;32(6):262-6.

16. Mcdonnell G, Russell AD. Antiseptics and disinfectants: activity, action, and resistance. Clin Microbiol Rev. 1999;12(1):147-79. Erratum in: Clin Microbiol Rev. 2001;14(1):227.

17. Hughes R, Kilvington S. Comparison of hydrogen peroxide contact lens disinfection systems and solutions against Acanthamoeba polyphaga. Antimicrob Agents Chemother. 2001;45(7):2038-43.

18. Rosenthal RA, Sutton SV, Schlech BA. Review of standard for evaluating the effectiveness of contact lens disinfectants. PDA J Pharm Sci Technol. 2002;56(1): $37-50$.

19. Gandhi PA, Sawant AD, Wilson LA, Ahearn DG. Adaptation and growth of Serratia marcescens in contact lens disinfectant solutions containing chlorhexidine gluconate. Appl Environ Microbiol. 1993;59(1):183-8.

20. Oplustil CP, Zoccoli CM, Tobouti NR, Sinto SI. Procedimentos básicos em microbiologia médica. São Paulo: Sarvier; 2000.

21. Trabulsi LR, Alterthum F, Gompertz OF, Candeias Neto JA. Microbiologia, $3^{\underline{a}}$ ed. São Paulo: Atheneu, 1999.

22. Miller MJ, Wilson LA, Ahearn DG. Effects of protein, mucin, and human tears on adherence of Pseudomonas aeruginosa to hydrophilic contact lenses. J Clin Microbiol. 1988;26(3):513-7.

23. Veyries ML, Faurisson F, Joly-Guillou ML, Rouveix B. Control of staphylococcal adhesion to polymethylmethacrylate and enhancement of susceptibility to antibiotics by poloxamer 407. Antimicrob Agents Chemother. 2000;44(4):1093-6.

24. Kanpolat A, Kalayci D, Arman D, Duruk K. Contamination in contact lens care systems. CLAO J. 1992;18(2):105-7.

25. Ifejika CP, Mclaughin-Borlace L, Lucas VJ, Roberts AD, Walker JT. Efficacy of a contact lens cleaning device and its enhancement of the performance of contact lens care products. Br J Ophthalmol. 2000;84(5):539-41.

26. Costerton JW, Cheng KJ, Geesey GG, Ladd TI, Nickel JC, Dasgupta M, et al. Bacterial biofilms in nature and disease. Annu Rev Microbiol. 1987;41:435-64.

27. Sweeney DF, Stapleton F, Leitch C, Taylor J, Holden BA, Willcox MD Microbial colonization of soft contact lenses over time. Optom Vis Sci. 2001; 78(2):100-5.

28. Johansen C, Falholt P, Gram L. Enzymatic removal and disinfection of bacterial biofilms. Appl Environ Microbiol. 1997;63(9):3724-8.

29. Lennette EH, Ballows A, Hausler Jr WJ, Shadomy HJ. Manual of clinical microbiology. $4^{\text {th }}$ ed. Washington D.C.: American Society of Microbiology; 1985.

30. Sutton SV, Franco RJ, Porter DA, Mowrey-Mckee MF, Busschaert SC, Hamberger JF, et al. D-value determinations are an inappropriate measure of disinfecting activity of common contact lens disinfecting solutions. Appl Environ Microbiol. 1991;57(7):2021-6. 